\title{
Caspases signal not only apoptosis but also antigen-induced activation in cells of the immune system
}

\author{
Kim Newton ${ }^{1}$ and Andreas Strasser ${ }^{2,3}$ \\ ${ }^{1}$ Molecular Oncology Department, Genentech Inc., South San Francisco, California 94080, USA; ${ }^{2}$ The Walter and Eliza Hall \\ Institute, 1G Royal Parade, Parkville, VIC 3050, Australia
}

Members of the caspase family of aspartate-specific cysteine proteases are best known for their involvement in apoptosis (human caspases 2, 3, 6, 7, 8, 9, 10; mouse caspases $2,3,6,7,8,9,12)$ and the maturation of cytokines such as IL-1 $\beta$ and IL-18 (human caspases 1, 4, 5; mouse caspases 1, 11; Thornberry and Lazebnik 1998; Shi 2002) . Recently, however, there have been a number of reports suggesting that caspases, in particular caspase 8 , may have an additional role in the immune system promoting lymphocyte activation and proliferation (Chun et al. 2002; Salmena et al. 2003). The seemingly paradoxical observations that caspase 8 is critical for both activation and death of cells of the immune system are the focus of this review.

Caspase 8 is required for death-receptor-induced apoptosis

Caspase 8 was first identified by virtue of its association with the adapter protein FADD (also called MORT1; Boldin et al. 1996; Muzio et al. 1996). This interaction recruits caspase- 8 zymogens into the "death-inducing signaling complexes" (DISCs) formed when death receptors belonging to the TNF receptor family are engaged by their cognate ligands and then bind the adaptor FADD (Fig. 1A; Kischkel et al. 1995, 2000; Medema et al. 1997; Bodmer et al. 2000; Sprick et al. 2000). Procaspase-8 molecules have a low level of enzymatic activity and their induced proximity within the DISC facilitates conformational changes necessary for their activation and autocatalytic processing (Medema et al. 1997; Martin et al. 1998; Muzio et al. 1998; Yang et al. 1998). Activation of caspase 8 triggers a cascade of caspase activation because substrates of the protease include the downstream "effector" caspases 3 and 7 (Srinivasula et al. 1996; Muzio et al. 1997). These effector caspases cleave vital cellular substrates culminating in the death of the cell.

${ }^{3}$ Corresponding author.

E-MAIL strasser@wehi.edu.au; FAX 61-3-9347-0852.

Article and publication are at http://www.genesdev.org/cgi/doi/10.1101/ gad.1077403.
Studies using FADD- or caspase-8-deficient cells, or cells from transgenic mice expressing specific inhibitors of these molecules, have established that FADD and caspase 8 are essential for apoptosis induction by the death receptors Fas, TNF-R1, DR3, TRAIL-R1, and TRAIL-R2 (Newton et al. 1998; Varfolomeev et al. 1998; Yeh et al. 1998; Kuang et al. 2000). Human caspase 10, for which there is no mouse counterpart, also has been observed in the Fas, TRAIL-R1, and TRAIL-R2 DISCs (Kischkel et al. 2001; Wang et al. 2001; Sprick et al. 2002). Caspase 10 resembles caspase 8 in that its prodomain is composed of two death effector domains (DEDs) that can bind to the DED in FADD. Whether caspase 10 can signal death-receptor-induced apoptosis in the absence of caspase 8 remains controversial (Kischkel et al. 2001; Wang et al. 2001; Sprick et al. 2002).

Certain cell types from mice lacking caspase 3 have some, albeit relatively minor, resistance to death-receptor-induced apoptosis (Woo et al. 1998). This resistance may indicate that substrates that are cleaved by downstream effector caspases, but not by the initiator caspase 8 , must be proteolyzed for cell death to occur efficiently. It will be interesting to see if cells lacking two or more effector caspases, such as caspases 3 plus 7, are completely resistant to Fas ligand (FasL) and other ligands of the TNF family.

Caspase 8 is essential for mouse embryo development but may be less critical in humans

Mice lacking caspase 8 (Varfolomeev et al. 1998; Sakamaki et al. 2002) or FADD (Yeh et al. 1998) are not viable beyond day 10-12 during embryo development, displaying hyperemia and heart defects. The cause of the embryonic lethality is not yet clear and it is not even known whether these abnormalities stem from impaired apoptosis because TUNEL staining failed to reveal differences between wild-type and FADD-deficient embryos (Yeh et al. 1998). It is noteworthy that the caspase-8 knock-out mice generated by Varfolomeev and colleagues (1998) lacked only the exons encoding the two DEDs, so it is theoretically possible that a p20- and p10containing polypeptide with proteolytic activity was ex- 
Figure 1. The role of FADD, caspase 8, and FLIP in apoptosis induction by death receptors. $(A)$ Oligomerization of death receptors by their cognate ligands precipitates formation of the death-inducing signaling complex (DISC). Essential components of the DISC are FADD and caspase 8. The death domain (DD) in FADD interacts with that in the cytoplasmic tail of the death receptor, while the death effector domain (DED) in FADD binds to a DED within the prodomain of caspase 8 . The induced proximity of caspase- 8 zymogens within the DISC promotes their autocatalytic activation, and active caspase 8 cleaves downstream effector caspases that dismantle the cell. (B) FLIP proteins are incorporated into the DISC, FLIP $_{\mathrm{L}}$ being cleaved. FLIP $\mathrm{S}$ and high levels of $\operatorname{FLIP}_{\mathrm{L}}$ appear to inhibit death-receptor-induced apoptosis, while low levels of FLIP $_{\mathrm{L}}$ may actually facilitate apoptosis signaling.
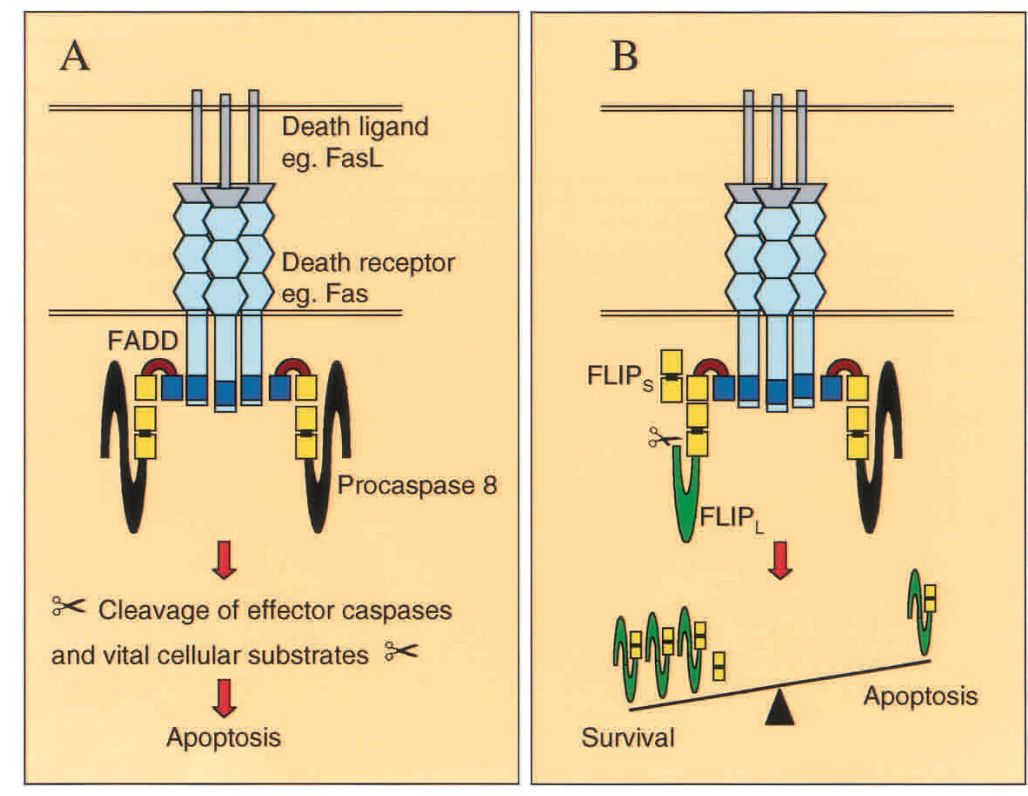

pressed in these animals and contributed to the early embryonic lethality. This possibility now appears less likely because a targeting strategy that precluded any caspase-8 protein expression also resulted in defects in early embryonic heart development and hematopoiesis (Salmena et al. 2003). Although caspase 8 is essential for normal mouse development, two humans have been identified that are homozygous for an inherited mutation that appears to render caspase 8 enzymatically inactive (Chun et al. 2002). It was proposed that caspase 10 in humans might perform the critical functions that are necessary for postnatal survival and can only be achieved by caspase 8 in the mouse. Alternatively, these patients might have very low levels of caspase- 8 activity that are sufficient for normal heart development but are too low for death-receptor-induced apoptosis, at least in lymphocytes.

\section{The enigmatic role of FLIP $_{S}$ and FLIP $_{L}$ in death receptor signaling}

The mammalian flip gene (also called casper, I-FLICE, flame-1, cash, MRIT, CLARP, and usurpin) is located adjacent to the caspase- 8 and -10 genes, and like its viral homologs, the vFLIPs, encodes proteins that are structurally related to caspases 8 and 10 (Bertin et al. 1996; Irmler et al. 1997; Thome et al. 1997). Alternative splicing of the mammalian flip gene gives rise to two proteins, the shorter FLIP $_{S}$ and the longer FLIP $_{\mathrm{L}}$. Mammalian FLIP $_{\mathrm{S}}$ and vFLIPs can inhibit death receptor signaling because they consist of two DEDs that compete with the DEDs of caspase 8 for binding to the DED in FADD (Bertin et al. 1996; Irmler et al. 1997; Thome et al. 1997). Mammalian FLIP $_{\mathrm{L}}$ comprises not only the two DEDs but also caspase-8-like p20 and p10 domains that lack enzymatic activity. FLIP $_{\mathrm{L}}$ gets cleaved within the DISC and has been postulated to block death receptor signaling by preventing further recruitment and activation of caspase 8 (Scaffidi et al. 1999). Interestingly, loss of FLIP in mice produces a similar embryonic lethal phenotype to a deficiency of caspase 8 or FADD (Yeh et al. 2000). This finding was surprising because experiments with transfected cells have indicated, for the most part, that FLIP and FLIP $_{\mathrm{L}}$ both function as inhibitors of death-receptorinduced apoptosis (Goltsev et al. 1997; Hu et al. 1997; Irmler et al. 1997; Srinivasula et al. 1997; Rasper et al. 1998). In some studies (Goltsev et al. 1997; Han et al. 1997; Inohara et al. 1997; Shu et al. 1997), however, they were shown to promote cell death. Recently, it was reported that only very high levels of $\operatorname{FLIP}_{\mathrm{L}}$ inhibit deathreceptor-induced apoptosis, whereas low levels promote activation of caspase 8 (Chang et al. 2002), perhaps by FLIP $_{\mathrm{L}}$ acting as an additional scaffold protein together with FADD (Fig. 1B). This finding probably reconciles the different functions that have been ascribed to FLIP $_{\mathrm{L}}$ based on various overexpression studies. Because flip knock-out mice that cannot make either FLIP isoform have a phenotype that is similar to that of caspase- 8 and fadd-null animals (Yeh et al. 2000), it appears that under physiological conditions flip functions predominantly as a proapoptotic gene. It has also been hypothesized that FADD, FLIP $_{\mathrm{L}}$, and caspase 8 might participate in a celldeath-independent signaling pathway during development (Yeh et al. 2000), and a similar process might operate in cells of the immune system (see below). The generation of mice lacking $\operatorname{FLIP}_{\mathrm{L}}$ but not FLIP $_{\mathrm{S}}$ or mice in which FLIP proteins can be removed in an inducible or cell-type-specific manner may shed more light on the role of these proteins.

\section{A role for caspase 8 in lymphocyte proliferation}

The first hint that caspase 8 might have a role in the immune system beyond regulating death-receptor-in- 
duced apoptosis came from the study of mice lacking normal FADD function in their T-lymphocytes. FADD knockout T-cells (from chimeric mice produced by injection of $\mathrm{fadd}^{-/-}$ES cells into $\mathrm{rag}-2^{-/-}$blastocycts) or transgenic T-cells expressing a dominant interfering mutant of FADD (FADD-DN) were, in addition to being completely resistant to FasL-induced apoptosis, unable to proliferate normally in response to mitogens or antigens (Newton et al. 1998, 2001; Walsh et al. 1998; Zhang et al. 1998; Zörnig et al. 1998). The abnormalities in $T$-cell activation were because of a cell intrinsic defect and could not be attributed to impaired IL-2 production, $\mathrm{Ca}^{2+}$ mobilization, NF- $\mathrm{\kappa B}$ activation, or MAPK signaling (Zhang et al. 1998; Newton et al. 2001; Mack and Häcker 2002). Although the tumor suppressor p53 was initially reported to be required for the reduced proliferation of FADD-DN T-cells (Zörnig et al. 1998), this could not be confirmed in later experiments (Newton et al. 2001). FADD-DN T-cells did undergo increased apoptosis following mitogenic stimulation, but loss of FADD function did not appear to result in a general survival defect because resting $\mathrm{T}$-cells died at the same rate as their wild-type counterparts in the absence of growth factors or after treatment with certain cytotoxic drugs (Newton et al. 1998; Newton and Strasser 2000). Thus, FADD was the first component of the apoptotic signaling pathway engaged by death receptors that was found to have also a distinct, essential role in promoting T-cell proliferation.

Because caspase 8 was known to act downstream of FADD in death-receptor-induced apoptosis, by association, it became the first candidate for transmitting the FADD-dependent proliferative signal in T-cells. One piece of evidence against caspase 8 being required for T-cell proliferation was that transgenic T-cells expressing crmA, an inhibitor of caspase 8, proliferated normally in response to mitogens (Smith et al. 1996; Newton et al. 1998; Walsh et al. 1998). The level of crmA protein in the T-cells was sufficient to inhibit apoptosis induced by FasL or anti-Fas antibodies (Smith et al. 1996; Newton et al. 1998), so it seemed reasonable to assume that inhibition of caspase 8 was complete. It is possible, however, that much lower levels of caspase- 8 activity are needed for T-cell proliferation than for death-receptorinduced apoptosis, and this might explain why $\operatorname{crm} A$ transgenic T-cells respond normally to mitogens. Curiously, although their T-cells were resistant to FasL, the crm $A$ transgenic mice did not develop the unusual $\mathrm{B} 220^{+}$ T-cell receptor (TCR)/CD3 ${ }^{+}$cells, lymphadenopathy and splenomegaly seen in Fas-deficient lpr mutant mice or FasL-deficient gld mutant mice (Smith et al. 1996; Newton et al. 1998; Walsh et al. 1998). One possible explanation for the absence of $1 p r$-like disease in the $\operatorname{crm} A$ transgenic mice is that crmA expression was restricted to T-lymphoid cells and, as a consequence, Fas-induced activation of caspase 8 in antigen-presenting cells occurred normally and eliminated the cells that might otherwise contribute to chronic T-cell stimulation.

The initial evidence for caspase participation in the signaling events leading to T-cell proliferation was based on the observation that chemical caspase inhibitors such as zVAD.fmk could inhibit mitogen-induced proliferation of human and mouse T-cells (Alam et al. 1999; Kennedy et al. 1999). Caspase 8 was a candidate for mediating signals required for $\mathrm{T}$-cell proliferation because low-level processing of caspase 8 , but not caspase 3 , was observed in human T-cells after $4 \mathrm{~h}$ of stimulation with suboptimal concentrations of anti-CD3 antibodies (Kennedy et al. 1999). Another study detected processed forms of caspase 8 and downstream effector caspases at later time points after T-cell stimulation (Alam et al. 1999). In this study, "viable" cells not stained by annexin-V were analyzed, but it cannot be excluded that the caspase processing observed in these experiments represented cells in the early stages of apoptosis. Indeed, it is difficult to imagine how a cell might activate caspases $3,6,7$, and 8 such that proteins critical to cell survival are not cleaved (see below).

Intriguing genetic evidence that caspase 8 might play a role in lymphocyte activation came from the study of human siblings exhibiting the lymphadenopathy, splenomegaly, and impaired Fas-induced apoptosis of peripheral blood lymphocytes (PBLs) that is associated with autoimmune lymphoproliferative syndrome (ALPS), yet distinct from most ALPS patients, they also had recurrent infections indicative of immunodeficiency /Chun et al. 2002). These unusual ALPS patients lacked mutations in the coding sequences of Fas, FasL, or caspase 10 but were found to be homozygous for a C-to-T transition in caspase 8 that altered arginine 248 to tryptophan. This mutant version of caspase 8 appeared to be enzymatically inactive because, unlike wild-type caspase 8 , it was unable to cleave the substrate DEVD-AMC and could not restore sensitivity to Fas-induced apoptosis in a caspase-8-deficient variant of the human Jurkat T-cell line. Loss of caspase- 8 activity readily explained the ALPS-like characteristics of the affected individuals but it was also proposed to be causative of defective B-, T-, and NK-cell activation. The investigators attempted to verify a requirement for caspase 8 in immune-cell activation by targeting caspase 8 in normal PBLs using RNA interference or antisense oligonucleotides. While a reduction in caspase- 8 mRNA was demonstrated, it is unclear whether caspase- 8 protein was reduced significantly in the cells and whether this had a bearing on surface expression of the T-cell activation markers CD69 and CD25. Expression of wild-type caspase 8 in PBLs from the caspase-8-deficient individuals also had minimal impact on their lack of responsiveness to mitogenic stimulation. The fact that lymphadenopathy and splenomegaly occurred in the caspase-8-deficient patients, and that T-lymphoblasts could be generated from their PBLs to assess their susceptibility to Fas-induced apoptosis, seemed to suggest that caspase 8 was not absolutely required for lymphocyte proliferation. Thus it remained possible that the immunodeficiency manifested by the caspase-8-deficient siblings was caused by some additional mutation or was a secondary consequence of their lymphadenopathy. With regard to the latter possibility, it is worth mentioning that the abnormal B220+TCR $\alpha$ / $\beta^{+} \mathrm{CD}^{-} 8^{-} \mathrm{T}$-cells, which make up a large portion of the 
lymphadenopathy in older $1 p r$ and gld mice, are unresponsive to antigens and most mitogens (Cohen and Eisenberg 1991).

A definitive answer as to whether caspase 8 is required for $\mathrm{T}$-cell proliferation came from the generation of $\mathrm{T}$ cell-specific caspase-8-deficient mice (Salmena et al. 2003). In these tcasp $8^{-/-}$animals, caspase 8 was deleted only from T-lymphoid cells and hence embryogenesis was normal. T-cell production in the thymus was unaffected by caspase- 8 deficiency, but tcasp $8^{-/-}$mice did have significantly fewer mature T-cells in the spleen and lymph nodes than normal mice, indicating that caspase 8 may be required for proliferation of mature T-cells but not developing pro-T-cells. Consistent with a requirement for caspase 8 in mature T-cell proliferation, tcasp $8^{-/-}$mice were unable to mount effective cytotoxic $\mathrm{T}$-cell (CTL) responses upon viral (LCMV) infection, and upon mitogenic stimulation in culture, tcasp $8^{-/-} \mathrm{T}$-cells proliferated less extensively than their wild-type counterparts. Interestingly, the reduction in proliferation of tcasp $8^{-/-}$T-cells (Salmena et al. 2003) was similar in magnitude to that observed for FADD-DN transgenic Tcells (Newton et al. 1998). Mitogen-stimulated T-lymphocytes lacking FADD or caspase 8 were both able to activate NF- $\mathrm{B}$ transcription factors and the MAP kinases ERK1 and 2 (Newton et al. 2001; Salmena et al. 2003), indicating that defects in these signaling pathways are not responsible for their impaired proliferation. In T-lymphocytes from both mutant mice, the defect in cell division seems to occur somewhere during transition from the resting G0 state to the first S phase of the cell cycle. Once cells are cycling $(\mathrm{G} 1 \rightarrow \mathrm{S} \rightarrow \mathrm{G} 2 \rightarrow$ $\mathrm{M} \rightarrow \mathrm{G} 1)$, FADD and caspase- 8 functions appear to be dispensable for growth in cell volume and proliferation (Newton et al. 1998; Salmena et al. 2003). These findings are consistent with the notion that FADD and caspase 8 act in the same pathway to promote T-cell proliferation.

Hakem and colleagues' (Salmena et al. 2003) analyses of caspase-8-deficient mouse T-cells provide strong evidence that caspase 8 is essential for T-cell proliferation. It remains to confirm genetically the earlier experiments with chemical caspase inhibitors indicating that proteolytic activity is critical for T-lymphocyte activation (Alam et al. 1999; Kennedy et al. 1999). Future studies might focus on mice heterozygous for a caspase- 8 allele that can be inactivated by expression of Cre recombinase and an allele that is mutated to encode caspase 8 with an active site cysteine $>$ alanine substitution. This strategy would allow normal mouse development as a result of wild-type caspase- 8 expression during embryogenesis (unless the $\mathrm{C}>\mathrm{A}$ mutated caspase 8 acts as a dominant interfering mutant) and Cre-mediated deletion of wildtype caspase 8 specifically in T-cells. The T-cells would continue to express the enzymatically dead caspase- 8 $\mathrm{C}>\mathrm{A}$ active-site mutant, and therefore could be used to determine whether a function of caspase 8 other than its proteolytic activity is critical for $\mathrm{T}$-cell proliferation. If these mutant T-lymphocytes failed to respond normally to mitogens, then this would prove beyond doubt that caspase-8-mediated proteolysis is essential for T-cell pro- liferation. The challenge will then be to identify the caspase- 8 substrates that are critical for T-cell proliferation and to find out how caspase 8 is prevented from activating the destructive caspase cascade in activated $\mathrm{T}$-cells. It is possible that differences in the magnitude of caspase- 8 activation and/or its subcellular localization determine whether caspase 8 promotes proliferation or commits cells to apoptosis. Perhaps caspase 8 concentrated in the DISC launches the caspase cascade with all its amplification mechanisms, while in T-cells induced to proliferate, caspase 8 is only activated in small amounts in specific locations within the cell (Fig. 2). T-cells have to rearrange their cytoskeletal structures to be able to proliferate, as demonstrated by the T-cell activation defects seen in mice and humans lacking the Wiscott-Aldrich syndrome protein (WASP; Snapper et al. 1998), which regulates the actin cytoskeleton. It is tempting to speculate that caspase-8-mediated proteolysis contributes to cytoskeleton rearrangements critical for normal responses of $\mathrm{T}$-cells to antigens or mitogens.

\section{FLIP and T-cell proliferation}

Another candidate for transmitting the FADD-dependent proliferative signal in mitogen- or antigen-stimulated T-cells is FLIP because it too can interact with FADD through its DEDs. While the effect of FLIP deficiency in T-cells has yet to be examined, two groups have studied the impact of enforced expression of FLIP $_{\mathrm{L}}$ in transgenic T-cells (Van Parijs et al. 1999; Kataoka et al. 2000; Lens et al. 2002). Surprisingly, the results of these two studies differed significantly. The approach taken by Van Parijs and colleagues (1999) was to reconstitute lethally irradiated recipient mice with bone-marrow cells that had been transduced with a retrovirus expressing a bicistronic mRNA for FLIP $_{\mathrm{L}}$ and GFP. Thus, it was possible to isolate GFP-expressing cells from the reconstituted animals and assess the effect of FLIP $_{L}$ expression on multiple hematopoietic cell lineages. Consistent with high levels of FLIP $_{L}$ acting to inhibit death-receptor-induced apoptosis, FLIP $_{\mathrm{L}}$ overexpressing $\mathrm{B}$ - and Tlymphocytes were resistant to killing by anti-Fas antibodies and, likely as a consequence of their reduced sensitivity to ligands for death receptors, older mice developed autoimmune disease and showed an accumulation of both B- and T-lymphocytes. However, enforced FLIP $_{\mathrm{L}}$ expression did not cause accumulation of the B220 ${ }^{+} \mathrm{TCR} / \mathrm{CD}^{+}$cells found in Fas-deficient lpr mutant mice. Of note, $\operatorname{FLIP}_{\mathrm{L}}$ had no effect on mitogen-induced proliferation of lymphocytes.

Tschopp and coworkers (Lens et al. 2002) analyzed Tcells from FLIP $_{L}$ transgenic mice. The level of FLIP $_{L}$ protein in the transgenic T-cells was able to inhibit FasLinduced apoptosis, albeit only partially, but in contrast to the earlier findings of Van Parijs et al. (1999), T-cell proliferation in response to mitogens was either compromised or enhanced dependent on the level of stimulation. Thus, FLIP $_{\mathrm{L}}$ appeared to inhibit proliferation under conditions that produced optimal proliferation of normal $\mathrm{T}$-cells but enhanced proliferation when the concentra- 
tion of mitogens was suboptimal (Lens et al. 2002). The nature of this dual response remains to be elucidated. The discrepancies between the two studies may be because of differences in levels of FLIP $_{\mathrm{L}}$ expression or because the fact that FLIP $_{\mathrm{L}}$ was only expressed in T-cells in the transgenic mice but in all hematopoietic cell types in the mice that were reconstituted with the FLIP $_{\mathrm{L}}$-expressing hematopoietic stem cells.

The inhibition of T-cell proliferation by a FLIP $\mathrm{L}_{\mathrm{L}}$ transgene is reminiscent of that seen in absence of normal FADD function. A second feature shared by FLIP $_{\mathrm{L}}$ and FADD-DN transgenic mice is a slight but reproducible reduction in the number of $\mathrm{CD}^{+}$peripheral T-lymphocytes (Newton et al. 1998, 2000; Lens et al. 2002). Given the similarities between these two mouse models and the caspase-8-deficient T-cells (Salmena et al. 2003), it is tempting to speculate that FLIP $_{\mathrm{L}}$ and FADD-DN proteins both inhibit $\mathrm{T}$-cell proliferation by preventing FADD from engaging caspase 8. A precise understanding of the role of $\mathrm{FLIP}_{\mathrm{L}}$ in T-cell proliferation will likely only emerge from the study of mutant mice in which FLIP $_{\mathrm{L}}$ is deleted in T-cells only.

\section{Death receptors and T-cell proliferation}

The signaling components that act upstream of FADD and caspase 8 to promote T-cell proliferation remain unclear. It is possible that FADD and caspase 8 act immediately downstream of the TCR/CD3 complex but this seems unlikely given that FADD-deficient and caspase8-deficient T-cells both show defective proliferation in response to PMA plus ionomycin (Newton et al. 1998; Salmena et al. 2003), which bypass engagement of the TCR/CD3 complex and activate downstream signaling mechanisms directly. Several groups have reported that
Fas can provide a costimulatory signal to T-cells exposed to suboptimal concentrations of anti-CD3 antibody (A1derson et al. 1993; Kennedy et al. 1999; Kataoka et al. 2000), but the ability of T-cells from Fas-deficient lpr mutant mice (prior to development of lymphadenopathy) to proliferate normally in response to mitogens (Newton et al. 1998) indicates that Fas signaling is not essential for T-cell proliferation. TNF-R1 also has been reported to transduce signals for cell proliferation (Mackay et al. 1994; Yamada et al. 1997) but T-cells lacking this death receptor appear to proliferate normally (Pfeffer et al. 1993; Rothe et al. 1993). Because mature T-cells may express several different death receptors with overlapping functions, absence of a single death receptor may not cause a proliferation defect because another death receptor can still provide the FADD/caspase-8-dependent signal. However, it remains possible that FADD and caspase 8 are activated in mitogen- or antigen-stimulated T-cells by a mechanism that does not involve death receptors (Fig. 2). This issue might be clarified by biochemical isolation and characterization of FADD- and caspase-8-associated proteins from activated T-cells.

In summary, there is now considerable evidence that FADD and caspase 8 are necessary not only for deathreceptor-induced apoptosis but also for normal T-cell proliferation. These findings raise questions as to how selective cleavage of substrates by caspase 8 might be achieved without activation of the caspase cascade leading to apoptosis. Elucidation of the signaling events that occur prior to and after FADD/caspase 8 engagement during T-cell activation, and further analysis of the role of $\mathrm{FLIP}_{\mathrm{L}}$ in this process, may provide novel targets for manipulation of immune-cell function in a therapeutic setting where it is desirable to switch on/off either proliferation or death.

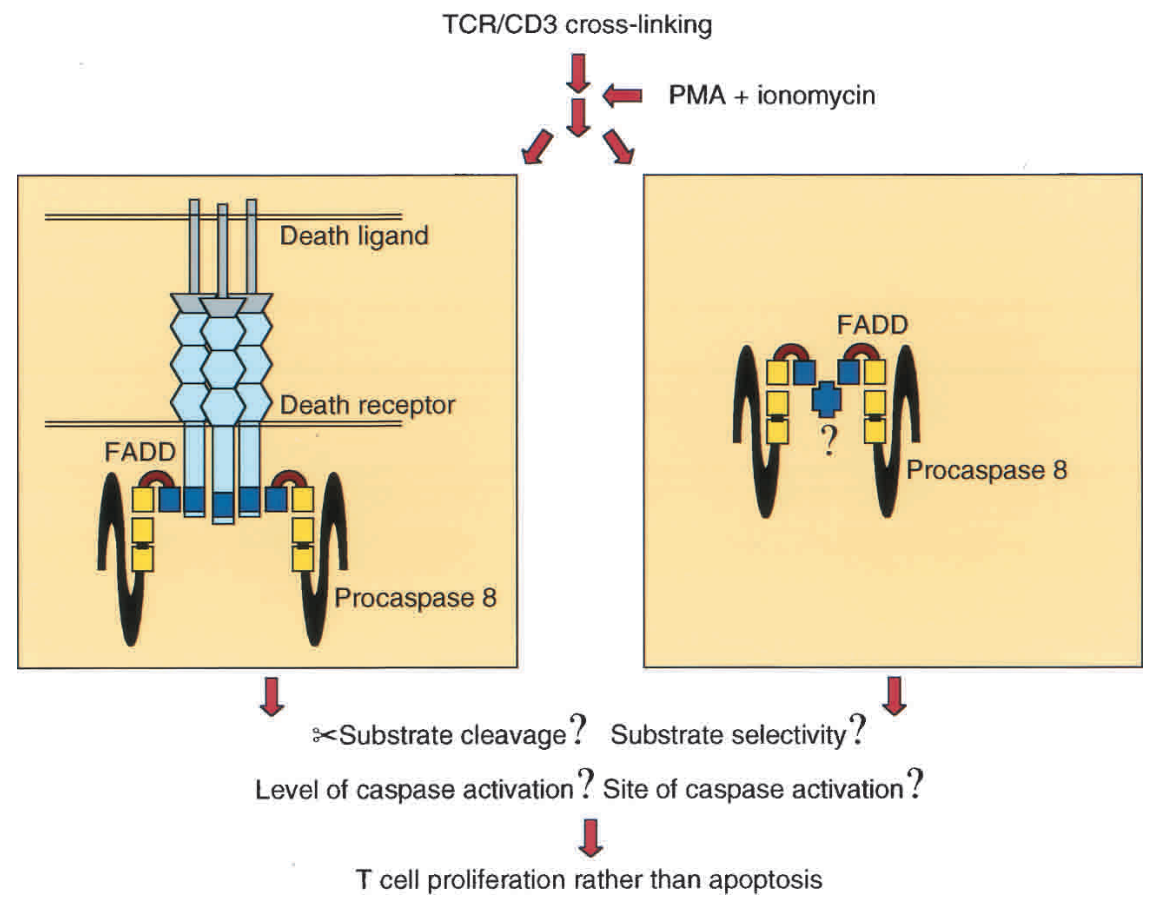

Figure 2. The role of FADD and caspase 8 in signaling $\mathrm{T}$-cell proliferation. FADDmediated aggregation of procaspase 8 leading to $\mathrm{T}$-cell proliferation may occur downstream of death-receptor engagement or independently of death receptors. It remains to be determined whether caspase- 8 proteolytic activity is required for T-cell proliferation, but if this is the case, then future studies will need to address how signals for exiting the quiescent state are generated without activation of the apoptotic caspase cascade. For instance, are there differences in where caspase 8 is activated within the cell, in which substrates are cleaved by caspase 8 , or is the magnitude of caspase- 8 activation much reduced? 


\section{Acknowledgments}

We thank all of our past and present colleagues, particularly J. Adams, S. Cory, D. Vaux, A. Harris, D. Huang, H. Puthalakath, M. Pellegrini, A. Ashkenazi, E. Varfolomeev, and V. Dixit for their help with our research and for discussions. Work in A.S.' laboratory is supported by grants and fellowships from the NHMRC (Canberra), the Dr. Josef Steiner Cancer Research Foundation (Bern, Switzerland), the Leukemia and Lymphoma Society of America, the Cancer Research Institute (New York), and the JDF/NHMRC.

\section{References}

Alam, A., Cohen, L.Y., Aouad, S., and Sekaly, R.P. 1999. Early activation of caspases during $\mathrm{T}$ lymphocyte stimulation results in selective substrate cleavage in nonapoptotic cells. $J$. Exp. Med. 190: 1879-1890.

Alderson, M., Armitage, R.J., Maraskovsky, E., Tough, T.W., Roux, E., Schooley, K., Ramsdell, F., and Lynch, D.H. 1993. Fas transduces activation signals in normal human $\mathrm{T}$ lymphocytes. J. Exp. Med. 178: 2231-2235.

Bertin, J., Armstrong, R.C., Ottilie, S., Martin, D.A., Wang, Y., Banks, S., Wang, G.-H., Senkevich, T.G., Alnemri, E.S., Moss, B., et al. 1996. Death effector domain-containing herpesvirus and poxvirus proteins inhibit both Fas- and TNFR1induced apoptosis. Proc. Natl. Acad. Sci. 94: 1172-1176.

Bodmer, J.L., Holler, N., Reynard, S., Vinciguerra, P., Schneider, P., Juo, P., Blenis, J., and Tschopp, J. 2000. TRAIL receptor-2 signals apoptosis through FADD and caspase-8. Nat. Cell Biol. 2: 241-243.

Boldin, M.P., Goncharov, T.M., Goltsev, Y.V., and Wallach, D. 1996. Involvement of MACH, a novel MORT1/FADD-interacting protease, in Fas/APO-1- and TNF receptor-induced cell death. Cell 85: 803-815.

Chang, D.W., Xing, Z., Pan, Y., Algeciras-Schimnich, A., Barnhart, B.C., Yaish-Ohad, S., Peter, M.E., and Yang, X. 2002. c-FLIP $_{\mathrm{L}}$ is a dual function regulator for caspase- 8 activation and CD95-mediated apoptosis. EMBO J. 21: 3704-3714.

Chun, H.J., Zheng, L., Ahmad, M., Wang, J., Speirs, C.K., Siegel, R.M., Dale, J.K., Puck, J., Davis, J., Hall, C.G., et al. 2002. Pleiotropic defects in lymphocyte activation caused by caspase- 8 mutations lead to human immunodeficiency. $\mathrm{Na}$ ture 419: 395-399.

Cohen, P.L. and Eisenberg, R.A. 1991. Lpr and gld: Single gene models of systemic autoimmunity and lymphoproliferative disease. Annu. Rev. Immunol. 9: 243-269.

Goltsev, Y.V., Kovalenko, A.V., Arnold, E., Varfolomeev, E.E., Brodianskii, V.M., and Wallach, D. 1997. CASH, a novel caspase homologue with death effector domains. J. Biol. Chem. 272: 19641-19644.

Han, D.K.M., Chaudhary, P.M., Wright, M.E., Friedman, C., Trask, B.J., Riedel, R.T., Baskin, D.G., Schwartz, S.M., and Hood, L. 1997. MRIT, a novel death-effector domain-containing protein, interacts with caspases and $\mathrm{BclX}_{\mathrm{L}}$ and initiates cell death. Proc. Natl. Acad. Sci. 94: 11333-11338.

Hu, S., Vincenz, C., Ni, J., Gentz, R., and Dixit, V.M. 1997. I-FLICE, a novel inhibitor of tumor necrosis factor receptor-1 and CD-95-induced apoptosis. J. Biol. Chem. 272: 1725517257.

Inohara, N., Koseki, T., Hu, Y., Chen, S., and Núñez, G. 1997. CLARP, a death effector domain-containing protein interacts with caspase- 8 and regulates apoptosis. Proc. Natl. Acad. Sci. 94: 10717-10722.

Irmler, M., Thome, M., Hahne, M., Schneider, P., Hofmann, K., Steiner, V., Bodmer, J.-L., Schröter, M., Burns, K., Mattmann,
C., et al. 1997. Inhibition of death receptor signals by cellular FLIP. Nature 388: 190-194.

Kataoka, T., Budd, R.C., Holler, N., Thome, M., Martinon, F., Irmler, M., Burns, K., Hahne, M., Kennedy, N., Kovacsovics, M., et al. 2000. The caspase-8 inhibitor FLIP promotes activation of NF-kB and Erk signaling pathways. Curr. Biol. 10: 640-648.

Kennedy, N.J., Kataoka, T., Tschopp, J., and Budd, R.C. 1999. Caspase activation is required for T cell proliferation. J. Exp. Med. 190: 1891-1896.

Kischkel, F.C., Hellbardt, S., Behrmann, I., Germer, M., Pawlita, M., Krammer, P.H., and Peter, M.E. 1995. Cytotoxicity-dependent APO-1 (Fas/CD95)-Associated proteins form a death-inducing signaling complex (DISC) with the receptor. EMBO J. 14: 5579-5588.

Kischkel, F.C., Lawrence, D.A., Chuntharapai, A., Schow, P., Kim, K.J., and Ashkenazi, A. 2000. Apo2L/TRAIL-dependent recruitment of endogenous FADD and caspase- 8 to death receptors 4 and 5. Immunity 12: 611-620.

Kischkel, F.C., Lawrence, D.A., Tinel, A., LeBlanc, H., Virmani, A., Schow, P., Gazdar, A., Blenis, J., Arnott, D., and Ashkenazi, A. 2001. Death receptor recruitment of endogenous caspase-10 and apoptosis initiation in the absence of caspase8. J. Biol. Chem. 276: 46639-46646.

Lens, S.M., Kataoka, T., Fortner, K.A., Tinel, A., Ferrero, I., MacDonald, R.H., Hahne, M., Beermann, F., Attinger, A., Orbea, H.A., et al. 2002. The caspase 8 inhibitor c-FLIP $\mathrm{L}_{\mathrm{L}}$ modulates $\mathrm{T}$-cell receptor-induced proliferation but not activation-induced cell death of lymphocytes. Mol. Cell. Biol. 22: 54195433.

Mack, A. and Häcker, G. 2002. Inhibition of caspase or FADD function blocks proliferation but not MAP kinase-activation and interleukin-2-production during primary stimulation of T cells. Eur. J. Immunol. 32: 1986-1992.

Mackay, F., Rothe, J., Bluethmann, H., Loetscher, H., and Lesslauer, W. 1994. Differential responses of fibroblasts from wild-type and TNF-R55-deficient mice to mouse and human TNF-a activation. J. Immunol. 153: 5274-5284.

Martin, D.A., Siegel, R.M., Zheng, L., and Lenardo, M.J. 1998. Membrane oligomerization and cleavage activates the caspase-8 (FLICE/MACHa1) death signal. J. Biol. Chem. 273: 4345-4349.

Medema, J.P., Scaffidi, C., Kischkel, F.C., Shevchenko, A., Mann, M., Krammer, P.H., and Peter, M.E. 1997. FLICE is activated by association with the CD95 death-inducing signaling complex (DISC). EMBO J. 16: 2794-2804.

Muzio, M., Chinnaiyan, A.M., Kischkel, F.C., O'Rourke, K., Shevchenko, A., Ni, J., Scaffidi, C., Bretz, J.D., Zhang, M., Gentz, R., et al. 1996. FLICE, a novel FADD homologous ICE/CED-3-like protease, is recruited to the CD95 (Fas/Apo1) death-inducing signaling complex. Cell 85: 817-827.

Muzio, M., Salvesen, G.S., and Dixit, V.M. 1997. FLICE induced apoptosis in a cell-free system. J. Biol. Chem. 272: 29522956.

Muzio, M., Stockwell, B.R., Stennicke, H.R., Salvesen, G.S., and Dixit, V.M. 1998. An induced proximity model for caspase-8 activation. J. Biol. Chem. 273: 2926-2930.

Newton, K. and Strasser, A. 2000. Ionizing radiation and chemotherapeutic drugs induce apoptosis in lymphocytes in the absence of fas or FADD/MORT1 signaling: implications for cancer therapy. J. Exp. Med. 191: 195-200.

Newton, K., Harris, A.W., Bath, M.L., Smith, K.G.C., and Strasser, A. 1998. A dominant interfering mutant of FADD/Mort1 enhances deletion of autoreactive thymocytes and inhibits proliferation of mature T lymphocytes. EMBO I. 17: 706718 . 
Newton, K., Harris, A.W., and Strasser, A. 2000. FADD/MORT1 regulates the pre-TCR checkpoint and can function as a tumour suppressor. EMBO J. 19: 931-941.

Newton, K., Kurts, C., Harris, A.W., and Strasser, A. 2001. Effects of a dominant interfering mutant of FADD on signal transduction in activated T cells. Curr. Biol. 11: 273-276.

Pfeffer, K., Matsuyama, T., Kündig, T.M., Wakeham, A., Kishihara, K., Shahinian, A., Wiegmann, K., Ohashi, P.S., Krönke, M., and Mak, T.W. 1993. Mice deficient for the $55 \mathrm{kd}$ tumor necrosis factor receptor are resistant to endotoxic shock, yet succumb to L. monocytogenes infection. Cell 73: 457-467.

Rasper, D.M., Vaillancourt, J.P., Hadano, S., Houtzager, V.M., Seiden, I., Keen, S.L.C., Tawa, P., Xanthoudakis, S., Nasir, J., Martindale, D., et al. 1998. Cell death attenuation by 'Usurpin', a mammalian DED-caspase homologue that precludes caspase- 8 recruitment and activation by the CD-95 (Fas, APO-1) receptor complex. Cell Death Differ. 5: 271288.

Rothe, J., Lesslauer, W., Lötscher, H., Lang, Y., Koebel, P., Köntgen, F., Althage, A., Zinkernagel, R., Steinmetz, M., and Bluethmann, H. 1993. Mice lacking the tumour necrosis factor receptor 1 are resistant to TNF-mediated toxicity but highly susceptible to infection by Listeria monocytogenes. Nature 364: 798-802.

Sakamaki, K., Inoue, T., Asano, M., Sudo, K., Kazama, H., Sakagami, J., Sakata, S., Ozaki, M., Nakamura, S., Toyokuni, S., et al. 2002. Ex vivo whole-embryo culture of caspase-8-deficient embryos normalize their aberrant phenotypes in the developing neural tube and heart. Cell Death Differ. 9: 1196-1206.

Salmena, L., Lemmers, B., Hakem, A., Matysiak-Zablocki, E., Murakami, K., Au, P.Y.B., Berry, D.M., Tamblyn, L., Shehabeldin, A., Migon, E., et al. 2003. Essential role for caspase 8 in T-cell homeostasis and T-cell-mediated immunity. Genes \& Dev. (this issue).

Scaffidi, C., Schmitz, I., Krammer, P.H., and Peter, M.E. 1999. The role of c-FLIP in modulation of CD95-induced apoptosis. J. Biol. Chem. 274: 1541-1548.

Shi, Y. 2002. Mechanisms of caspase activation and inhibition during apoptosis. Mol. Cell 9: 459-470.

Shu, H.-B., Halpin, D.R., and Goeddel, D.V. 1997. Casper is a FADD- and caspase-related inducer of apoptosis. Immunity 6: 751-763.

Smith, K.G.C., Strasser, A., and Vaux, D.L. 1996. CrmA expression in $\mathrm{T}$ lymphocytes of transgenic mice inhibits CD95 (Fas/APO-1)-transduced apoptosis, but does not cause lymphadenopathy or autoimmune disease. EMBO J. 15: 5167-5176.

Snapper, S.B., Rosen, F.S., Mizoguchi, E., Cohen, P., Khan, W., Liu, C.-H., Hagemann, T.L., Kwan, S.-P., Ferrini, R., Davidson, L., et al. 1998. Wiskott-Aldrich syndrome protein-deficient mice reveal a role for WASP in T but not B cell activation. Immunity 9: 81-91.

Sprick, M.R., Weigand, M.A., Rieser, E., Rauch, C.T., Juo, P., Blenis, J., Krammer, P.H., and Walczak, H. 2000. FADD/ MORT1 and caspase- 8 are recruited to TRAIL receptors 1 and 2 and are essential for apoptosis mediated by TRAIL receptor 2. Immunity 12: 599-609.

Sprick, M.R., Rieser, E., Stahl, H., Grosse-Wilde, A., Weigand, M.A., and Walczak, H. 2002. Caspase-10 is recruited to and activated at the native TRAIL and CD95 death-inducing signalling complexes in a FADD-dependent manner but can not functionally substitute caspase-8. EMBO J. 21: 4520-4530.

Srinivasula, S.M., Ahmad, M., Fernandes-Alnemri, T., Litwack, G., and Alnemri, E.S. 1996. Molecular ordering of the Fasapoptotic pathway: The Fas/APO-1 protease Mch5 is a
CrmA-inhibitable protease that activates multiple Ced-3/ ICE-like cysteine proteases. Proc. Natl. Acad. Sci. 93: 14486-14491.

Srinivasula, S.M., Ahmad, M., Ottilie, S., Bullrich, F., Banks, S., Wang, Y., Fernandes-Alnemri, T., Croce, C.M., Litwack, G., Tomaselli, K.J., et al. 1997. FLAME-1, a novel FADD-like anti-apoptotic molecule that regulates Fas/TNFR1-induced apoptosis. J. Biol. Chem. 272: 18542-18545.

Thome, M., Schneider, P., Hofmann, K., Fickenscher, H., Meinl, E., Neipel, F., Mattmann, C., Burns, K., Bodmer, J.-L., Schröter, M., et al. 1997. Viral FLICE-inhibitory proteins (FLIPs) prevent apoptosis induced by death receptors. Nature 386: $517-521$.

Thornberry, N.A. and Lazebnik, Y. 1998. Caspases: Enemies within. Science 281: 1312-1316.

Van Parijs, L., Refaeli, Y., Abbas, A.K., and Baltimore, D. 1999. Autoimmunity as a consequence of retrovirus-mediated expression of c-FLIP in lymphocytes. Immunity 11: 763-770.

Varfolomeev, E.E., Schuchmann, M., Luria, V., Chiannilkulchai, N., Beckmann, J.S., Mett, I.L., Rebrikov, D., Brodianski, V.M., Kemper, O.C., Kollet, O., et al. 1998. Targeted disruption of the mouse caspase 8 gene ablates cell death induction by the TNF receptors, Fas/Apo1, and DR3 and is lethal prenatally. Immunity 9: 267-276.

Walsh, C.M., Wen, B.G., Chinnaiyan, A.M., O'Rourke, K., Dixit, V.M., and Hedrick, S.M. 1998. A role for FADD in T cell activation and development. Immunity 8: 439-449.

Wang, J., Chun, H.J., Wong, W., Spencer, D.M., and Lenardo, M.J. 2001. Caspase-10 is an initiator caspase in death receptor signaling. Proc. Natl. Acad. Sci. 98: 13884-13888.

Woo, M., Hakem, R., Soengas, M.S., Duncan, G.S., Shahinian, A., Kagi, D., Hakem, A., McCurrach, M., Khoo, W., Kaufman, S.A., et al. 1998. Essential contribution of caspase 3/CPP32 to apoptosis and its associated nuclear changes. Genes \& Dev. 12: 806-819.

Yamada, Y., Kirillova, I., Peschon, J.J., and Fausto, N. 1997. Initiation of liver growth by tumor necrosis factor: Deficient liver regeneration in mice lacking type I tumor necrosis factor receptor. Proc. Natl. Acad. Sci. 94: 1441-1446.

Yang, X., Chang, H.Y., and Baltimore, D. 1998. Autoproteolytic activation of pro-caspases by oligomerization. Mol. Cell 1: 319-325.

Yeh, W.C., Pompa, J.L., McCurrach, M.E., Shu, H.B., Elia, A.J., Shahinian, A., Ng, M., Wakeham, A., Khoo, W., Mitchell, K., et al. 1998. FADD: Essential for embryo development and signaling from some, but not all, inducers of apoptosis. Science 279: 1954-1958.

Yeh, W.C., Itie, A., Elia, A.J., Ng, M., Shu, H.B., Wakeham, A., Mirtsos, C., Suzuki, N., Bonnard, M., Goeddel, D.V., et al. 2000. Requirement for Casper (c-FLIP) in regulation of death receptor-induced apoptosis and embryonic development. Immunity 12: 633-642.

Zhang, J., Cado, D., Chen, A., Kabra, N.H., and Winoto, A. 1998. Fas-mediated apoptosis and activation-induced T-cell proliferation are defective in mice lacking FADD/Mort1. Nature 392: 296-300.

Zörnig, M., Hueber, A.-O., and Evan, G. 1998. p53-dependent impairment of T-cell proliferation in FADD dominant-negative transgenic mice. Curr. Biol. 8: 467-470. 


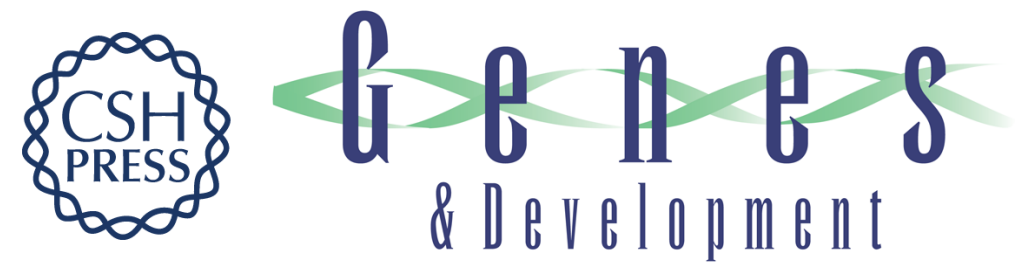

\section{Caspases signal not only apoptosis but also antigen-induced activation in cells of the immune system}

Kim Newton and Andreas Strasser

Genes Dev. 2003, 17:

Access the most recent version at doi:10.1101/gad.1077403

References This article cites 56 articles, 28 of which can be accessed free at: http://genesdev.cshlp.org/content/17/7/819.full.html\#ref-list-1

License

Email Alerting

Receive free email alerts when new articles cite this article - sign up in the box at the top Service right corner of the article or click here.

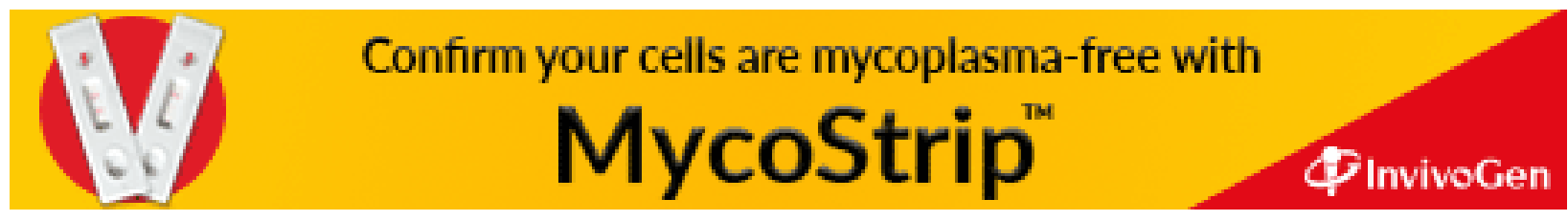

